\section{OPEN ACCESS}

Edited and reviewed by:

Laura Lorenzoni,

University of South Florida,

United States

${ }^{*}$ Correspondence:

Svetlana N. Losa

Svetlana.Losa@AWI.de

Specialty section:

This article was submitted to

Ocean Observation

a section of the journal

Frontiers in Marine Science

Received: 25 July 2017

Accepted: 28 July 2017

Published: 07 August 2017

Citation:

Losa SN, Soppa MA, Dinter T, Wolanin A, Brewin RJW, Bricaud A,

Oelker J, Peeken I, Gentili B,

Rozanov V and Bracher A (2017)

Corrigendum: Synergistic Exploitation

of Hyper- and Multi-Spectral Precursor

Sentinel Measurements to Determine

Phytoplankton Functional Types

(SynSenPFT). Front. Mar. Sci. 4:258.

doi: 10.3389/fmars.2017.00258

\title{
Corrigendum: Synergistic Exploitation of Hyper- and Multi-Spectral Precursor Sentinel Measurements to Determine Phytoplankton Functional Types (SynSenPFT)
}

\begin{abstract}
Svetlana N. Losa ${ }^{1 *}$, Mariana A. Soppa ${ }^{1}$, Tilman Dinter ${ }^{1,2}$, Aleksandra Wolanin ${ }^{2}$, Robert J. W. Brewin ${ }^{3,4}$, Annick Bricaud ${ }^{5,6}$, Julia Oelker ${ }^{2}$, Ilka Peeken ${ }^{1}$, Bernard Gentili ${ }^{5,6}$, Vladimir Rozanov ${ }^{2}$ and Astrid Bracher ${ }^{1,2}$

${ }^{1}$ Alfred Wegener Institute, Helmholtz Centre for Polar and Marine Research, Bremerhaven, Germany, ${ }^{2}$ Institute of Environmental Physics, University of Bremen, Bremen, Germany, ${ }^{3}$ Plymouth Marine Laboratory, Plymouth, United Kingdom, ${ }^{4}$ Plymouth Marine Laboratory, National Centre for Earth Observation, Plymouth, United Kingdom, ${ }^{5}$ Sorbonne Universités, UPMC-Université Paris-VI, UMR 7093, Laboratoire d'Océanographie de Villefranche, Observatoire Océanologique, Villefranche-sur-Mer, France, ${ }^{6}$ Centre National de la Recherche Scientifique, UMR 7093, LOV, Observatoire Océanologique, Villefranche-sur-Mer, France
\end{abstract}

Keywords: synergistic, Sentinel, satellite retrievals, phytoplankton functional type

\section{A corrigendum on}

Synergistic Exploitation of Hyper- and Multi-Spectral Precursor Sentinel Measurements to Determine Phytoplankton Functional Types (SynSenPFT)

by Losa, S. N., Soppa, M. A., Dinter, T., Wolanin, A., Brewin, R. J. W., Bricaud, A., et al. (2017). Front. Mar. Sci. 4:203. doi: 10.3389/fmars.2017.00203

In the original article, we neglected, but would like to acknowledge the North-German Supercomputing Alliance (HLRN) for providing HPC resources that have contributed to the research results reported in this paper. The authors apologize for this error and state that this does not change the scientific conclusions of the article in any way.

Conflict of Interest Statement: The authors declare that the research was conducted in the absence of any commercial or financial relationships that could be construed as a potential conflict of interest.

Copyright () 2017 Losa, Soppa, Dinter, Wolanin, Brewin, Bricaud, Oelker, Peeken, Gentili, Rozanov and Bracher. This is an open-access article distributed under the terms of the Creative Commons Attribution License (CC BY). The use, distribution or reproduction in other forums is permitted, provided the original author(s) or licensor are credited and that the original publication in this journal is cited, in accordance with accepted academic practice. No use, distribution or reproduction is permitted which does not comply with these terms. 